\section{A cobertura jornalística nas eleições municipais de 1996 em Caxias do Sul}

Cassiano Francisco S. de Oliveira Mestrando em Comunicação Social FAMECOS/ PUCRS

\section{A hipótese de agenda-setting}

ATÉ MEADOS DA DÉCADA de 60, a discussão existente sobre os mass media delineava as pessoas.

Nas décadas anteriores, a partir da teoria hipodérmica, quando iniciaram as primeiras pesquisas sobre a comunicação de massa, havia uma espécie da rejeição quanto aos efeitos da audiência.

O divisor deáguas equepassou a reformular o pensamento neste campo de pesquisa, deu-se em 1972, quando os professores de jornalismo e pesquisadores Maxwell McCombs e Donald L. Shaw publicaram um estudo ${ }^{1}$ sobre o que os meios de comunicação impõem aos receptores e que são qualificados conforme o interesse da coletividade.

A pesar deexistirem dúvidas sobrea exatidão de quando foi publicado o primeiro trabal ho com o agenda-setting, atribui-se a esta dupla como sendo a pioneira desta área.

A través da leitura deuma obra publicada em 1922 por Walter Lippmann, Public O pinion, McCombs chega à origem teórica do seu trabalho.

Basicamente em que consiste a teoria da hipótese de agenda-setting?

A definição mais didática sobre este termo podemos atribuir a Clóvis de Barros Filho, em seu livro Ética na Comunicação: da 
informação ao receptor:

“As pessoas agendam seus assuntos e suasconversasemfunção do queamídia veicula. É o que sustenta a hipótese do agenda-setting. Trata-se de uma das formaspossíveisdeincidênciadamídia sobre o público. É um tipo de efeito social da mídia. É a hipótese segundo a qual a mídia, pela sel eção, disposição e incidência de suas notícias, vem determinar os temas sobre os quais o público falará e discutirá."2

Na opinião deste autor, a mídia acaba nos impondo uma espécie de menu coletivo das informações, impedindo que outros temas venham a ser conhecidos pelo público. Se verificarmososresultadosobtidospelamídia, constaremos que se sobressaem os temas comuns, que são aqueles mais conhecidos pelos ditos agentes sociais. Barros Filho entende que a própria mídia acaba por menosprezar os temas menos conhecidos.

A discussão estabelecida a partir da década de 60 procurava delinear um processo de interação entreo poder damídiaeseus efeitos imediatos. As pesquisas surgi das a partir da décadade40não davamenfoquea estetópico. Além de Lippmann, outros autores, como Robert Park, entre 1925 e 1940, se colocavam simpáticosao temaabordado, dequeosmeios de comunicação definiam uma preferência temática deseusassuntos. Masésomenteem 1958, conforme Clóvis de Barros Filho, quea hipótese de agenda-setting é enunciada pela primeira vez:

“De certa forma, o jornal é o primeiro motor da fixação da agenda territorial. Eletemgrandeparticipaçãona definição do que a maioria das pessoas conversarão, o queaspessoaspensarão quesão os fatos e como devem lidar com os problemas." 3

Em 1963, Bernard Cohen menciona no estudo The press and foreign policy que a imprensa não tem o que impor o pensar mas seguramente impõem sobre o que pensar.

Outrosestudiososdofenômenocontribuíram para que este processo se desenvolvesse. Foi o caso dos sociólogos KurteGladys Lang que apontavam para o fato damídiafornecer uma grande quantidade de informação que os receptores (ou espectadores, como queiram) absorvem apesar de existirem dúvidas sobre a idéia de que a imprensa tivesse grande capacidade de modificar as atitudes das pessoas. Também enunciavam que a mídia por construir, na sua essência, imagens públicasdefiguraspúblicas, estavasugerindo aos indivíduos o que pensar e saber.

Ao referir-se a estas obras, Clóvis de Barros Filhomencionaqueemborafossempioneiros no campo da pesquisa comunicacional, não representou mérito específico, visto que são citados pelo fato de terem sido antecessores da hipótese de agenda-setting.

Como foi escrito anteriormente, o primeiro estudo sobrea mesma hipótesefoi publicado em 1972, pelosprofessores McCombseShaw. Esta pesquisa ocorreu no outono de 1968, duranteas el eições presi denciais americanas disputadas por N ixon, WallaceeHumphrey, na localidade de Chapell Hill, Carolina do N orte e procedeu da seguinte forma:

“Entre 18 de setembro e 6 de outubro cem entrevistas foram realizadas. Para seleção destas, cem respostas com uma questão filtro foram usadas para identificar aqueles que não tinham até aqui decidido deforma definitiva como votar - presumivelmente aqueles mais abertos ou sensíveis às informações de campanha, aos indecisos.(...) Tomando emprestado a estratégia de Trenaman e McQuail, este estudo indagou a cada entrevistado para contornar os temas chaves como eles os viam, displicentemente do que os candidatos podiam estar dizendo naquele momento." 4 
Além das entrevistas, foram analisadoscinco jornais, dois canais detelevisão edois jornais semanais quenoticiavam a campanha. A fim de estabelecer uma regulamentação de critérios, foi adotada a seguinte forma: para televisão, matériasquedurassem 45 segundos ou mais; nos jornais, as matérias que apareciam em primeira página ou por fim, nas revistas o que aparecesse no início da secção da revista.

As críticas a este estudo foram basicamente cal cadas na incapacidade de provar "o nexo causal entrea agenda da mídia ea agenda do público. Ou seja, não é pelo fato de que haja coincidência temática que, necessariamente, são os meios que agendam o público." ${ }^{5}$

A única forma quefoi tomada por McCombs e Shaw a fim de garantir este nexo foi 0 intervalo de duas semanas, o que foi considerado insuficiente para garantir a anterioridade dos meios. Ou seja, o período entre a coleta do material informativo e a coleta das respostas dos entrevistados. Um dos primeiros resultados a que chegaram foi a não sintonia entre as notícias sobre as campanhas apresentadas pela mídia e a campanha eleitoral em si própria.

Segundo McCombs e Shaw6, "este é satisfatório como um primeiro teste de hipótese de agenda-setting, mas subseqüente pesquisa deve mover um largo plano social para o plano psicológico, equiparando atitudes individuais com o uso individual da mídia".

Umoutracrítica sobreesta pesquisa partiu de outrosdoisconceituados pesquisadoressobre os mass mídia: Melvin L. DeFleur e Sandra Ball-Rokeach. N umensaio ${ }^{7}$ publicadoem 1983 , el estecem críticas decunho construtivo sobre esta pesquisa de Chappel Hill:

"Se os entrevistados tivessem sido escolhidos casualmente entre os membros da comunidade, os aposentados poderiam ter sido incluídos, bem como osnão eleitores. Alémdisso, (...), existem evidências muito grandes de que os eleitores decidem em quem votar logo no início dacampanha. Em tais pessoas, o efeito de agendamento seria bem menor. As pessoas que esperam para fazer uma escolha apenas depois de todosos tópicosserem cuidadosamente examinados(atravésdosnoticiários) são uma minoria e a amostra deste estudo tentou focalizar exatamente estas pessoas. Entretanto, o significado da incrível correlação ainda precisa ser determinado. Contudo, existe base suficiente para a hipótese de que foi encontrado algum tipo de efeito agenda." 8

Os resultados col hidos pela dupla McCombs eShaw não os desistimulou a realizar futuras pesquisasnosmoldescomo o deChapell Hill. A provaéquequatro anos depois, em 1972, os americanos novamente tinham uma nova eleição presidencial. Richard Nixon buscava a reel eição, tendo como opositor o democrata George McGovern. Nesta pesquisa, tanto McCombsquantoShaw buscaramaperfeiçoar a pesquisa anterior, concedendo um prazo maior depesquisa, referenteao levantamento de dados, ainda que o foco central fosse o mesmo de Chapell Hill, mas aprofundado.

N ovamenteumacidadedaCarolinado N orte foi eleita para sediar a pesquisa: Charlotte. ConformeDeFleur eBall-Rokeach, trêsfatores acabaram por definir o nome da referida cidade. O primeiro foi o fator geográfico estar localizadaforadainfluênciadasgrandes metrópoles, estando entre Washigton e Atlanta, na Geórgia. Charlotte estava fora da influência da grande mídia. "Na verdade, havia apenas dois jornais e três canais de televisão em Charlotte. Sua população, em 1970, era de 354 mil habitantes, grande o suficiente para diversidade mas pequena o suficiente para que pudessem ser obtidas amostrada de toda a população votante". ${ }^{9}$

O segundo fator colocado pela dupla de pesquisadores relaciona também o fator 
geográfico. Localizada no sul dos Estados Unidos, uma das regiões menos desenvolvidas daquele país, era uma cidade bastante desenvolvida para os padrões sulistas. Ao invés de população constituída basicamentepor famílias, ela apresentava, na época, uma população de migrantes vindos de outras localidades.

Porfim, oterceirofator: ao contrário degrande parte do sul onde os democratas tradicionalmente preval ecem, em Charlotte acabou acontecendo o contrário: ganhou o candidato republicano Richard Nixon.

As principais descobertas desteestudo foram dividas em cinco tópicos. O primeiro, denominado Esclarecendo a definição, coloca em discussão por Shaw eMcCombsocaminho da cognição, fazendo quea conscientização e a função de abastecimento da informações por parte da mídia sejam importante. Faz comqueforneçaumaexplicaçãoeumaclareza no campo teórico, justificando o processo pelo qual a mídia participa do processo pela construção da realidade a que serve a audiência. Mas esta é uma realidade de segundo plano, reconstruída pela própria mídia, onde a mesma reconstrução ocorre através da economia enunciativa da mídia, definindo o agendamento pessoal enquanto audiência.

Importantemencionar quetanto aseconomias enunciativas dos mass media, quanto aquilo quevai ser divulgado, não acontecemao acaso. Existe a necessidade do veículo em atrair e prender a atenção da audiência e também a necessidade de compreender que o agendamento dos mass mídia e a construção do agendamento pessoal fazem parte de um complexo sistema social.

O segundo fator denomina-se fontes da informação nas agendas pessoais. Conforme levantaram os pesquisadores, as discussões interpessoais também são fontes de agendamento pessoal. A principal fonte era o noticiáriodacampanhaconformetransmitido pelas redes de televisão e por al guns jornais.

Mauro Wolf coloca de maneira mais aprofundadaestetópico. Para ele, o procedimento padrão deste tipo de pesquisa estabelece de forma comparativa a agenda dos mass media com a agenda do público, fazendo de forma analítica uma avaliação conjunta dos meios decomunicação como dos destinatários. Wolf destaca a citação de McCombs, publicada originariamente em $1981^{10}$, e posteriormente transcrita em seu livro Teorias da Comunicação: ${ }^{11}$

“A hipótese do agenda-setting desenvolve-se a partir de um interesse geral pelo modo como as pessoas organizam e estruturam a realidade circundante. $A$ metáfora do agenda-setting é uma macrodescrição deste processo(...). Essa metáfora paira sobre certos pressupostos e interrogações específicos acerca do tipo de estratégias que os sujeitos utilizam ao estruturarem o seu próprio mundo. Por exemplo, a típica avaliação da agenda dos mass mídia - quearticula os temas segundo a freqüência com que são mencionados- baseia-seno pressuposto de que a freqüência com que um tema ou um assunto aparece, é uma indicação importante utilizada pelos destinatários para avaliarem a sua importância."

O terceiro fator captado por McCombs e Shaw, seqüência do tempo no processo de agendamento, remete à seguinte questão: a imprensa agenda a audiência ou a audiência agenda a imprensa?

Esta pergunta levou os pesquisadores a val orizarem o tempo, chegando ao seguinte resultado: no início da pesquisa havia menor coincidência entre a agenda da mídia e a agenda pessoal da audiência do que ao final da campanha. Conforme as premissas de DeFleur e Ball-Rokeach, os jornais parecem ter um papel claro na modelagem deagendas de eleitores durante o período estudado. 
Estetópico éaprofundado por Wolf na suajá citada obra. O autor relata a pesquisa de M clureePatterson quena mesma campanha presidencial de 1972, e publicada também em 1976,12 comprovou queo público absorveu menos as experiências televisivas do que outrosmeiosdecomunicação como osjornais e os spots publicitários. Estes dois teóricos apontavam para uma confirmação, embora limitada, do agenda-setting. A nalisando com maior profundidade, Wolf menciona que os noticiáriostelevisivoseasnotíciasjornalísticas são diferentes. As primeiras têm como característica serem breves, rápidas e heterogêneas, além de estarem acumuladas num efeito temporal, ou seja, não sendo demasiadamente suficientes para o efeito do agenda-setting. Já as notícias publicadas na imprensa possuem uma eficácia mais duradoura devido à capacidade de maior absorção por parte dos receptores.

Mauro Wolf entende tratar-se de uma integração entreo queo agen da-setting aborda e outras correntes de pesquisa a partir da "análise se estender às pressões e condições produtivas-profissionais que vinculam a feitura dos textos difundidos pela comunicação de massa." ${ }^{13}$

Há um outro trabalho mais aprofundado, realizado também por Patterson e McClure em 1976, sobre o impacto da televisão sobre os conhecimentos doseleitores. N esteestudo, os autores afirmam que temas principais envolvendo as el eições são relegados a segundo plano e os temas folclóricos, assim como os embates entre candidatos, acabam sendo preferidos pela mídia, quando não a monopolizando como um único assunto:

"A informação televisiva quotidiana fornece, portanto, uma situação de aprendizagem impossível: o público é assediado por informações fragmentárias, totalmente inaptas para constituírem um quadro cognitivo adequado às opções queo el eitorado échamado a fazer." ${ }^{14}$
A gendamento e características pessoais é o quarto fator originário desta pesquisa. Neste caso, McCombs e Shaw perceberam, pelas entrevistas realizadas, que alguns el eitores tendiam a repetir o agendamento da mídia mais seguidamente que outros. Eles viram três fatores básicos para que isto se concretizasse: nível de interesse dos eleitores no conteúdo, nível de incerteza que os assuntos revelam e 0 esforço requerido para localizar uma informação relevante.

Os dois primeiros fatores foram agrupados num conceito formulado pela dupla de pesquisadores que se denominou necessidade de informação. Este termo significa uma necessidadedeinformação transformadaem um fator de personalidade que leve o indivíduo à mídia. "Uma hipótese simples podeser formada então, dequequanto maior esta necessidade, maior a atenção. Esta, por sua vez, levaria a um aumento da influência do agendamento." 15

No mesmo estudo de Charlotte, os dados obtidos confirmaram que quando os fatores de incerteza e relevância são medidos em diversas formas, os diferentes níveis de necessidadeseinterligam, conformeosníveis de exposição, à mídia e à força do agendamento.

Por fim, avaliando o papel do agendamento político, trata de acrescentar ao relacionamento entre Estado e mídia, através do agendamento, uma parte do processo de comunicação pelo qual os indivíduos desenvolvem e compartilham significados políticos.

Conforme avaliam Defleur e Ball-Rokeach:

“Ao mesmo tempo, o agendamento não define a mídia como transmissora passiva da informação que transmite notícias sobre eventos políticos, candidatosetópicos, aos eleitores. A mídiaé formadora de significados de suas próprias conviç̧ões. Elaéo agenteativo 
que seleciona, mostra, interpreta e enfatiza eaté, possivel mente distorce o fluxo de informação sobre os eventos políticos de um lado do sistema e os eleitores, sedentos de informação do outroladodosistema. A imprensainjeta seu próprio significado nas suas reportagens antes de apresentá-las à audiência. Seus consumidores, por sua vez, desenvolvem entre s, várias interpretações compartilhadas (cultura popular) sobre a campanha, os candidatos e os tópicos em questão. Além disso os principais tomadores de decisão são descritos como consumidores desta realidade construída socialmente. As criações da imprensa se tornam para eles fontes importantes de informação, sobreaqual eles baseiam, emníveisnão especificados, suasposiçõespolíticasea sua política. Em outras palavras, a imprensa também molda a cultura política da elite." 16

Caso o papel da imprensa estiver certo, o poder de dominação é impressionante. No entanto, "se a imprensa realmente tem este poder, de moldar os dois lados do processo político, ainda precisa ser constatado."17

A discussão entre o sistema da mídia e o sistemapolítico éo principal temadadifusão massiva.

No já citado estudo deClóvis deBarros Filho sobre agenda-setting, ele remete à "précanalização dasinformações". Estefenômeno objetiva num primei ro momento, o "agendamento dos consumidores de produtos políticos (onde a informação política mediatizada ocupa lugar de destaque" ${ }^{18}$

Assim, adotando este tema, conclui que:

"Se o trabalho propriamente político se confunde com a imposição de uma representaçãolegítimado mundosocial ideal dentro de um mercado de oferta política onde o consumo se confunde com a adesão, a mediatização deste ou daquele 'fato político' éa vitrina deque necessita o produto político para ser adquirido." 19

Através de um processo sistemático, utilizando idéias de David Easton, o autor estabelecea seguinter lação: o universo social transmite ao sistema político demandas e apoios que são filtrados, classificados e ordenados para impedir o engarrafamento das demandas, no caso, partidos políticos e associações representativas de classe.

Este processo é descrito da seguinte forma por Clóvis de Barros Filho:

"As demandas, previamente filtradas, são endereçadas à 'caixa negra', onde são transformadas em decisões e ações políticas. Essas últimas poderão ou não ser transformadas em produtos informativos, ou seja, poderão ou não ser canalizadaspelosmeiosdedifusão. Essa canalização tem incidência direta sobre o sistema político porque o retorno (feedback) de uma decisão política mediatizada é completamente distinto do retorno de uma decisão não canalizada pelos meios. O feedback de uma decisão política dependerá sempre da sua absorção pelo sistema informativo."20

A nalisando estesmecanismoscomo detalhes, percebemos porque o papel da mídia no mundo contemporâneo é tão presente e também justifica sua estratégia perante a sociedadeeperanteoEstado. MelvinDeFleur e Sandra Ball-Rokeach relacionaram sete pontos de variáveis dependentes e independentes no processo de agendamento:

“1. Eleitores apresentam aumento nos padrões do uso da comunicação de massa no decorrer das campanhas.

2. Estes padrões de aumento de exposição ao conteúdo da mídia apresentam 
variações entre os diferentes tipos de eleitores, definidas por características pessoaisdistintasediferentescategorias sociais.

3. Cadatipo demídia (jornais, televisão) tem um papel diferente, como fonte da informação, nosváriostiposdeeleitores.

4. O aumento da exposição à mídia durantea campanha pareceaumentar o interesse sobre a política entre os eleitores e ajuda a definir as saliências da campanha para os eleitores.

5. Devido ao aumento do uso da mídia, e à saliência, há um aumento na comunicação interpessoal sobre a política durante a campanha.

6. O aumento da exposição à mídia e à comunicação interpessoal leva a um aumento da necessidadedeinformação e orientação sobre política, durante a campanha, a qual, por sua vez, estimula a mais exposição da mídia e a mais comunicação interpessoal.

7. A influência do agendamento nas diferentes categorias de eleitores é, portanto, um produto deexposição, tipo de mídia, interesse, saliência, necessidade de informação e comunicação interpessoal." 21

A importância da hipótese de agenda-setting está em superar teorias que definem a comunicação social como al go incontrolável, manipulador e redutor do homem.

O agendamento aborda formas clássicas como o Estado, os eleitores, as questões políticas, bem como o papel da imprensa neste contexto. Teorias calcadas na psicologia social e na sociologia acabaram por submeter o papel do jornalismo a uma ortodoxia discutível, a um processo hermético, não levando em contaa dinâmica da comunicação.
2 Um estudo de caso: eleição para prefeito de 1996 em Caxias do Sul - RS

O assunto escolhido para aplicação da hipótese de agenda-setting foi a eleição para prefeito em Caxias do Sul no ano de 1996, e que teve Pepe Vargas, da Frente Popular formadapeloPartido dosTrabalhadores(PT); Partido Popular Socialista (PPS); Partido SocialistaBrasileiro(PSB) ePartido Comunista do Brasil (PC do B) - el eito com 90.792 votos ( $49,04 \%$ ) do total de 185.126 eleitores. ${ }^{22}$

Em segundo lugar ficou Germano Rigotto da FrenteDemocráticaintegrada pelosseguintes partidos políticos: Partido do Movimento Democrático Brasileiro (PMDB); Partido da Frente Liberal (PFL), Partido Liberal (PL) e Partido da Social Democracia Brasileira (PSDB). O candidato alcançou 86.763 votos válidos correspondendo a 46, 87 por cento do eleitorado.

Situada a 122 quilômetros de Porto Alegre, Caxias do Sul possui em torno de $350 \mathrm{mil}$ habitantes. Está localizada na Encosta Superior do Nordeste e colonizada basicamente por imigrantes italianos. A cidade tem no seu pólo metal-mecânico a mola propulsora de sua economia. Mas também o comércio ea agroindústria fazem partedeste panorama, embora em escala menor.

A lém da disputa acirrada entre os dois candidatos citados, a eleição contribuiu para o agendamento dos meios de comunicação no Estado e também fora dele, já que as duas candidaturasrepresentavamideologicamente forças tradicionamente rivais na política: Vargas pelo PT e Rigotto pelo PMDB. Importante ressaltar que os dois candidatos disputaramaeleição no primeiroturnotendo dois outros adversários: Luis Carlos Festugatto peloPartidoTrabal histaBrasileiro(PTB) e Mario Grazziotin pela Unidade Popular Progressista ( composta pelo Partido Democrático Trabal hista-PDT - ePartido Popular Progressista - PPB). 
Um outro detal he explorado pelos meios de comunicação foi o grau de parentesco dos dois candidatos ( são primos).

Outracoincidência: tantoPepeVargasquanto Germano Rigotto disputaram eleições para a prefeitura de Caxias do Sul. Rigotto em 1988 eVargas em 1992. A mbos não ganharam nas respectivas vezes em que disputaram.

A extrema polarização do eleitorado foi o fator principal do agendamento por parteda mídia e que durante a realização desta pesquisa foi comprovada. Como exemplo, citamos a matéria publicada pelo jornal local Pioneiro no dia 25 de outubro, quando os dois candidatos já estavam em plena campanha para o segundo turno.

No caso, tratava-se de uma entrevista sobre pesquisaseleitorai $\varsigma^{23}$ eo entrevistado eraJ oão Inácio Pires Lucas, mestre em Ciências Políticas pela UFRGS e professor da universidadelocal (UniversidadedeCaxias do Sul), com a tese A Oligarquização dos Partidos: O rganização Interna do PT e do PM DB no Rio Grande do Sul.

A matéria ocupava um grande destaque naquela edição - página inteira. Mas o que chama a atenção é o fato do jornal ter procurado uma pessoa com formação acadêmica a fim de opinar sobre a política local. Eis um trecho:

“'DiriaqueCaxiaséumacidadeatípica', adiantao professor, referindo-seaograu depolitização da comunidade. Em 1976 e1989, aUFRGSefetuou duas pesquisas em cidades de porte semelhante pelo Brasil e constatou um alto índice de conscientização em Caxias. 'Existeuma grandesofisticação política nas pessoas aponto delaselaboraremopiniõessobre aconjunturanacional eestadual, etrazêlas para nível local', justifica" ${ }^{24}$

Para o professor éimportante a identificação dascategoriassociaispara determinar o objeto final de uma pesquisa a fim de conhecer as tendências do eleitorado:

"Se a eleição fosse distrital, Pepe teria ganho em muitos distritos. Mas não podemos dizer que ele é o candidato dos pobres." 25

João Inácio PiresLucasapontatrêstendências existentes no processo eleitoral que determinam qual seja o quadro político: o interesse local, a pessoa do candidato e a polarização do pleito, embora não represente novidade, lembra Pires Lucas, ao dizer quena época do bipartidarismo a polarizaçãojáacontecera de formasemel hanteàquesedesenhavanaquele instante. Enquanto o PT assumiaum discurso progressistaepopulista, oPMDB enveredava para o perfil conservador.

Ao avaliar a situação do eleitor, o cientista político não esquece de um detalhe:
“'Não existe esquerdização do eleitor- ado, nem direitização'argumenta, ao afirmar que a única homogeneidade possível éatendênciahistórica. Jáqueo eleitor não constrói por conta própriaas relações conjunturais, entram em jogo os meios de comunicação, incapazes de fazer sozinhos a transmissão da relação. (grifo do redator). 'Os partidos são fundamentais, ainda mais que em uma eleição municipal as necessidades são mais reais', esclarece."26

O grifo nadedaração do professor deCiências Políticas traz novamente à discussão do que já foi escrito anteriormente, envolvendo o eleitorado, osmeios decomunicação demassa e o Estado.

A pós esta introdução, iniciamos agora a descrição do processo da pesquisa sobre a hipótese da agenda-setting nas eleições para prefeito na cidade de Caxias do Sul.

Estrategicamente, a eleição era importante para os dois partidos políticos que disputam ahegemonianocenário político doRioGrande 
do Sul: o PT e o PMDB.

Foram analisados dois jornais diários, sendo um de circulação regional - Pioneiro, pertencente a RBS - e outro de circulação estadual, sediado em Porto Alegre - Correio do Povo. Foi sugerida a análise também do jornal Correio Riograndense. A não inclusão deste veículo deve-se à dificuldade em encontrar grande parte dos exemplares editados à época das eleições.

Quanto aosdiasanalisados-conhecido como frame temporal - vai do início da campanha eleitoral, nodia 02deagosto, atéo dia seguinte aotérmino dosegundoturno: 16denovembro. Importante mencionar que o Pioneiro não circula aos domingos, por isso asua edição de sábado tem incluída a data do dia seguinte.

Jáno início da pesquisa percebemos um certo descompasso entre as duas publicações: o Pioneiro anuncia na capa em chamada de 3 linhas ematéria de $1 \mathrm{col} \times 13,5 \mathrm{~cm}$ mais 4 fotos e 1 box , o início da campanha em Caxias do Sul. Enquanto o Correio do Povo publica somente no dia 18 de agosto uma matéria sobre a eleição de Caxias: "Caxias faz hoje eleição simulada", ocupando $1 \mathrm{col}$ x 8,5 cm.

Nodiaseguinte, 04 deagosto, Pioneiro publica com destaqueo caderno El leições 96 dequatro páginas, com um perfil dosquatro candidatos a prefeito. A capa do caderno estampa o seguinte título: “Estes guris não estão para brincadeira". Além do título, a fotografia dos quatro quando criança. Masamatériainterna "Inicia a temporada de caça ao voto" é um preâmbulo de agendamento em torno das eleições:

“A 60dias damaior eleição paraprefeito dahistóriado município, as campanhas começam a esquentar. A disputa voto a voto, a possibilidade de realização do segundo turno e a votação eletrônica são ingredientes que motivam quatro candidatos.(...) Eles agora lutam para conquistar o eleitorado. A tendência, apostam unânimes, é de que o término dosJogosOlímpicosdeAtlantaeo início da propaganda gratuita no rádio e televisão irão direcionar as atenções da população para 3 de outubro."27

A edição seguinte do Pioneiro, 9 de agosto, traz na sua capa uma chamada sobre as el eições: "População demonstra desinteresse". A matéria interna publicada na capa do caderno Eleições 96 publica resultado de pesquisadol bope, real izadaem fins dejunho nascidades deCaxiasdoSul, Bento Gonçalves, Lajeadoe Gramado. O resultado deCaxias do Sul afirmava que " $60 \%$ dos 400 entrevistados em Caxias disseram que possuem nenhum ou pouco interesse. A penas $16 \%$ responderam que têm muito interesse, e outros $21 \%$ médio." 28

No dia 17 de agosto, Pioneiro publica o resultado da pesquisarealizada pelol bope. A manchete de capa: Rigotto segue na frente em Caxias do Sul. Na página $6 \mathrm{com} 1 \mathrm{col} \times 17 \mathrm{~cm}$ e o título é I bope aponta liderança de Rigotto. $O$ resultado é38\% para Rigotto, 31\% para Pepe, 4\% para Mario Grazziotin e 2\% para Festugatto. Mas o que nos chamou a atenção não foi propriamenteesta matéria esim uma matéria minoritária- ocupando $3 \mathrm{col} \times 3,5 \mathrm{~cm}$ - publicadanamesmapágina6, tendo otítulo "Caxiense dá nota 5,6 para governo Britto". Era o resultado de uma outra pesquisa realizada pelo Ibope entre os dias 13 e 14 de agosto - portanto durante o período de propaganda eleitoral. A lém do título, ondea nota mediana para o governador Antônio Britto - pertencente ao mesmo partido do candidato Germano Rigotto (PMDB), uma constatação: aumenta o número de pessoas muito ou medianamente interessadas na eleição: $54 \%$ contra $37 \%$ da pesquisa anterior realizada pelo mesmo I bope.

A pós esta edição, o jornal Pionei ro publica na sua edição de 31 deagosto a terceira pesquisa do Ibope. A manchete de $2 \mathrm{col} \times 14,5 \mathrm{~cm}$ anuncia: "Nova pesquisa dá empate de Rigotto e Pepe". Na reportagem publicada 
no caderno Eleições 96, “I bope aponta empate entre Pepe e Rigotto" - ocupando 2 col x 12,5 cm da respectiva edição, a colocação é a seguinte: em primeiro lugar, empatados com $38 \%$ cada um, Pepe e Rigotto. Em terceiro lugar, Mario Grazziotin com 3\% e em quarto Luis Carlos Festugatto com 2\%. Comparado coma pesquisa anterior, Rigotto estabilizou e Pepe subiu 6 pontos percentuais. A reportagemtambémmencionaumaoutra pesquisa também realizada pelo Ibope junto ao eleitorado que aponta um interesse maior pelaeleição: $56 \%$ de 400 pessoasentrevistadas afirmaram ter muito ou médio interesse pel o pleito.

Na mesma edição uma outra matéria "I bope aponta como será segundo turno" revela que PepeVargas venceria Rigotto por $44 \%$ contra $41 \%$.

Decorrido um mês de campanha eleitoral no município de Caxias do Sul, este era o panorama político. Enquanto que o jornal Pioneiro publicava estas duas pesquisas, 0 outro jornal, Correio do Povo, nos dias analisados nada publicou nos mesmos dias do Pioneiro. É um sinal que a eleição ainda não entrou num estágio adiantado de agendamento, limitando-se à cidade e à região.

O Correio do Povo vai publicar as primeiras matérias- entreos dias anal isados- na edição de 7 de setembro. "Comício de Rigotto acaba com pancadaria etiros" é publicada na página 2 , ocupando $1 \mathrm{col} \times 5 \mathrm{~cm}$. O texto era sobreum incidente ocorrido num bairro de Caxias do Sul, onde um ocupante de uma moto, com a bandeira do PT teria disparado dois tiros e um simpatizante do candidato Rigotto foi ferido por uma facada atribuídaa um petista. A mesma notícia foi veiculada na edição do Pioneiro de segunda-feira, 9 de setembro.

A outra matéria publicada pelo Correio com o mesmo espaço ena mesma página era sobre militantes do PT de Porto Alegre que organizaram umacaravanarumoaCaxiasdo
Sul com a finalidade de reforçar a campanha local.

No dia 13 de setembro, Pioneiro traz como chamada de capa: "Pesquisa acirra disputa entre Pepe e Rigotto". No caderno Eleições $96^{29}$ trazia matéria sobre debate ocorrido no dia anterior (quinta-feira) quando foi divulgada a quarta pesquisa do Ibope, onde Pepe Vargas ultrapassou Rigotto.

Finalmente, no dia 15 de setembro, o Correio do Povo publica a primeira matéria em destaque sobre as el eições de Caxias do Sul. Nem Pepe, nem Rigotto, mas algo que interessa a ambos: a divisão do PPB entre apoiar oPDT ou apoiar PepeVargas. A matéria "PPB vai ser decisivo em Caxias" ocupou 3 col x 4,5cm e foi publicada na página 2 .

Enquanto o Correio começava a dar uma maior atenção à eleição de Caxias, ainda que timidamente, Pioneiro publicava matérias com o cotidiano da disputa entre Rigotto e Pepe Vargas.

N a edição de 20 desetembro, P ionei ro publica a manchete: "Sucessão em Caxias ganha o Brasil". Na capa do caderno Eleições 96, em destaque o titulo "Temas nacionais centralizam o debate", e ocupando $3 \mathrm{col} \times 7,5 \mathrm{~cm}$ a matéria descrevia com ar de ufanismo:

“O primeiro debate promovido pela Rádio Gaúcha com candidatos à prefeituradeummunicípio dointerioralterou a estratégia dos quatro concorrentes à chefia do Executivo de Caxias do Sul, ontem à tarde. Pepe Vargas (Frente Popular), Germano Rigotto (Frente Democrática), MárioGrazziotin(Unidade Popular Progressista) e Luis Carlos Festugatto(PTB) abordaramtemassobre a economia nacional, investimentos do governofederal noEstado edesemprego para mostrar as diferenças entre seus projetosdeadministração municipal." 30

Independente do debate ter sido promovido 
por uma rádio pertencente ao mesmo grupo que controla o jornal Pioneiro, podemos afirmar que o agendamento em torno da el eição municipal passa para uma esferamais ampla, já que este debate ocorre fora do município, mais precisamente na capital do Estado, e, como aponta a matéria, afronta temas ligados à esfera nacional. Na mesma edição, épublicada uma outra reportagem no mesmotom: avisitadeM ichel Temer(PMDB) e Tarso Genro(PT), que no dia anterior estiveram na cidade para apoiar os dois candidatos à prefeitura. O espaço ocupado por esta matériaéde $2 \mathrm{col} \times 13,5 \mathrm{~cm}$ mais duas fotos.

N a edição de 27 de setembro os dois jornais analisados publicam - pela primieira vez no frametemporal- matériasemambasascapas. O Correio do Povo destaca o índice de 43,1\% dos votos para Pepe Vargas e de 35,2\% para Rigotto. A pesquisa realizada pelo centro de pesquisado própriojornal ocupa $3 \mathrm{col} \times 3,5 \mathrm{~cm}$ mais um box de $2 \mathrm{col} \times 4,5 \mathrm{~cm}$. O Pioneiro, por sua vez, destaca um tema comunitário: a segurança. "Eleitor de Caxias pede prioridade à segurança". Na capa do caderno Eleições 96, tendo como título "Segurança é a prioridade para o eleitor" e ocupando $3 \mathrm{col} x$ $12,5 \mathrm{~cm}$ mais 2 boxes e uma foto, a matéria destaca pesquisa realizada pelo I bope entre 600 pessoas nos dias 21 a 23 de setembro. Conforme a matéria, dos 600 entrevistados, 32 por cento foram assaltados. No mesmo caderno, na página 3, uma matéria sobre os candidatos intensificando comícios com a aproximação do dia da eleição.

O primeiro editorial sobreasel eições no frame temporal da pesquisa é publicado na edição do Pioneiro de 28 e 29 de setembro.

O editorial Segurança municipal (1 col x 9 cm) faz consi derações à matéria publicada no dia anterior sobre a insegurança. Uma outra matéria "É hora da cartada final" aborda os preparativos finais envolvendo os quatro candidatos para a el eição de 3 de outubro. A edição posterior ao dia da eleição - 4 de outubro - destaca o segundo turno em Caxias do Sul. O Pioneiro publica em manchete este histórico momento político. Em manchetena capa "Caxias terá segundo turno" com 3 col x $8 \mathrm{~cm}$ e internamente abrindo três páginas do caderno Eleições 96 - capa com título igual à manchete e uma página para o candidato Pepe Vargas: "Pepe vê situação confortável", $1 \mathrm{col} \times 28 \mathrm{~cm}$ euma para o candidato Germano Rigotto: "Rigotto projeta vantagem", com 4 col $\times 7 \mathrm{~cm}$. Também o editorial "Civismo" - 1 col $\times 15 \mathrm{~cm}$ - destaca as eleições e elogiando eleitores: "O eleitorado caxiense, como de todososgaúchos, confirmou queestámaduro para a prática democrática".

O Correio do Povo não abre tanto espaço para a disputa, mas anuncia na capa o segundo turno e num caderno especial sobre eleições destaca na página 5 : "Caxias vive disputa acirrada" com $4 \mathrm{col} \times 8 \mathrm{~cm}$ e duas fotos.

A partir deagora, com a eleição de Raul Pont para a prefeitura de Porto Alegre, o jornal passa a dar mai or destaquetanto para Caxias do Sul quanto para Pelotas, cidadesondeirão ocorrer segundo turno.

A edição de 5 e 6 de outubro continua destacando a eleição municipal. O Pioneiro estampa na capa: "PMDB elege a maior bancada". Também o editorial "Tradição cívica" enaltece o fator segundo turno. Além disto, a matéria sobre as eleições: "A puração confirma vantagem de Pepe" , e duas entrevistas realizadas com ambos os candidatos: "Rigotto aposta na vantagem dos votos" e "P epe V argas não mudará estratégia", ambas de página inteira. O Correio do P ovo também é objetivo: "Pepe e Rigotto partem para a decisão", é manchete da editoria de política com $1 \mathrm{col} \times 7,5 \mathrm{~cm}$ e $2 \mathrm{col} \times 3 \mathrm{~cm}$ mais duasfotos dos candidatos com familiares.

Definido o segundo turno, iniciam a fase de articulação deambos os candidatos em busca de apoio político. Será basicamente este assunto predominantenasedições posteriores à eleição do primeiro turno (11, 12 e 13 de 
outubro).

No dia 18 de outubro, o jornal Pioneiro destaca importantes fatos sobre o segundo turno: a divisão do PTB em apoiar Pepe Vargas ("Segundo turno racha PTB caxiense") e o apoio de Brizola a Pepe: "Brizola torce para vitória de Pepe". Paradoxalmente o mesmo jornal publica na página 10 "Circunstância impede união PT/PDT" sobre as dificuldades de aliança dos dois partidos. Enquanto que em Caxias tendem a se apoiarem, em Pelotassão adversários. Correio do Povo publica a manchete de capa com o resultado da sua primeira pesquisa após o primeiro turno: "Pepe lidera em Caxias do Sul”, com 49,9\% contra 39,7\% pró Rigotto.

$\mathrm{Na}$ edição de fim de semana, 19 e 20 de outubro, Pioneiro publica resultado da pesquisado Ibope: "Pepelarga nafrenteno 2 음 turno", ocupando página inteira. Pepelidera com $52 \%$ contra $37 \%$ a favor de Rigotto. Também traz publicadas duas matérias envolvendo apoio aos dois candidatos.

Um problema da maioria das cidades - a saúde - é matéria em que se mostra os principais problemasqueo novo prefeito terá de enfrentar. "Saúde desafia o próximo prefeito", matéria de página inteira, aborda a questão da saúde no município e traz dois boxes com a proposta dos dois candidatos na área. Foi publicada na página 6 do Pioneiro de 25 de outubro. Na mesma edição saiu entrevista com o cientista político a qual nos referimos no início deste capítulo. A edição do dia seguinte do mesmo jornal traz em destaque o resultado da pesquisa do Ibope, em queaponta empatetécnico entreRigotto e PepeVargas. O resultado de $47 \%$ contra $44 \%$ de Rigotto acirra cada vez mais a disputa entre os dois candidatos, é a essência da matéria, publicada na página 10.

A edição de 2 e 3 de novembro do Pioneiro traz como manchete o resultado da pesquisa entre Pepe Vargas e Germano Rigotto: "A umenta para sete pontos a diferença de
Pepe sobre Rigotto". Na mesma edição, o resultado da pesquisa em página inteira.

Das edições pesquisadas nesteperíodo, tanto do Correio do Povo quanto do Pioneiro, o destaque maior foi a cobertura do segundo jornal no também segundo debate real izado fora deCaxias do Sul. Desta vez, o jornal deu amplo destaque: o total de 6 páginas e a cobertura de 4 repórteres, além do fotógrafo. A edição de 8 de novembro traz como manchete: "D ebate esquenta campanha" com $2 \mathrm{col} \times 3 \mathrm{~cm}$. O caderno E leições 96 estampa na capa: "O primeiro duelo do segundo turno" com $4 \mathrm{col} \times 7 \mathrm{~cm}$. Nas páginas 2 e 3, "Os principais trechos do confronto" com 4 col $x$ $25 \mathrm{~cm}$ mais duas fotos e mais dois boxes. $\mathrm{Na}$ página 4 "0 Ambiente dos Bastidores" em 1 col $\times 24 \mathrm{~cm}$ mais um box de $1 \times 21 \mathrm{~cm}$ e 3 fotos. Por fim na contracapa com $2 \mathrm{col} \times 8,5 \mathrm{~cm}$ e quatro fotos além de um artigo do editor chefe do Pioneiro "Caxias ganha com 0 debate", elogiando o nível do debate.

No dia seguinte, o Pioneiro traz nova manchete de capa: "Pesquisa revela empate técnico": $46 \%$ para Pepe contra 44\% para Rigotto. Além de destacar o resultado em página inteira, uma outra matéria destaca a presença de duas personalidades em Caxias do Sul: o senador José Fogaça e o deputado Paulo Paim, ambos atuando como cabos eleitorais, respectivamente para Rigotto e Pepe. O Correi o do P ovo também veicula este fato, mas não coloca em destaque.

No dia da eleição, a manchete do Pioneiro resume o espírito da eleição: “A eleição do século" em $2 \mathrm{col} \times 7 \mathrm{~cm}$ mais um box de $2 \mathrm{col}$ $x 7 \mathrm{~cm}$, ondeépublicadoresultadodasúltimas pesquisas. Na página 6, o editorial “A palavra final das urnas" destaca em $2 \mathrm{col} \times 17 \mathrm{~cm}$ as eleições para segundo turno em todo o Brasil. O caderno Eleições 96 é todo dedicado à disputa entre Rigotto e Pepe. Na página 2, a matéria "A hora da decisão" com 2 col x 10cm, enquanto na página 3amatéria “Ú Itima chance para conquistar os votos" com $4 \mathrm{col} x$ $9 \mathrm{~cm}$ mais duas fotos. Nas duas páginas 
seguintes, umensaio fotográfico dacampanha e que ocupa toda a página. Por fim, na contracapa, o artigo do editor - chefe, Claudio Thomas, intitulado "Primos brigam por Caxias do Sul", em $4 \mathrm{col} \times 4 \mathrm{~cm}$ mais foto.

Enquanto o Pioneiro seconcentravanaeleição local, o outro jornal analisado seconcentrava nas el eições de Pelotas também. $O$ destaque ficou para Caxias, na página 2, com a manchete: "Briga nas ruas e cartórios de Caxias" com $1 \mathrm{col} \times 7,5 \mathrm{~cm} \mathrm{e} 2 \mathrm{col} \times 2,5 \mathrm{~cm}$ mais duas fotos. Outras duas matérias pequenas compunham o noticiário sobre a campanha: "O dia esperado por Pepe e Rigotto" e "Panfletos causam nova polêmica", ambas de $1 \mathrm{col} \times 2,5 \mathrm{~cm}$.

Na última edição, tanto Pioneiro quanto Correio do Povo estamparam as eleições nas suas capas. O segundo publicou: "PT vence em Caxias e PDT ganha em Pelotas" com 1 col $\times 9,5 \mathrm{~cm}$ e mais dois boxes. Na página 6 , a manchete é "Líderes ao lado de Pepe na vitória" com $1 \mathrm{col} \times 8 \mathrm{~cm}$ e $2 \mathrm{col} \times 3 \mathrm{~cm}$ mais duas fotos. Embaixo a matéria "Cidade viveu festa democrática" com $2 \mathrm{col}$ x 6,5 cm.

O Pioneiro destacou a vitória dePepeVargas. $\mathrm{Na}$ capa, em foto inteira, o prefeito eleito olhando para a cidade que vai governar nos próximos quatro anos ea seguintemanchete: "Estrela de Pepe brilha em Caxias". Na página 12, o editorial "As lições do segundo turno"destacava os prefeitos eleitos nas cidades onde ocorreram segundo turno, incluindo Pelotas e, é claro, Caxias do Sul. Mas foi no caderno Eleições 96 que o jornal deu ampla cobertura à eleição. Das oito páginas da publicação, sete foram dedicadas à eleição eà vitória dePepe Vargas. Na capa, a matéria é "Pepe festeja antes da apuração" em $2 \mathrm{col} \times 15,5 \mathrm{~cm}$ e uma foto. A página 2 "Pepe projetou a vitória no início do dia" em $1 \times 24 \mathrm{~cm}$ mais uma foto. $N$ as páginas 4 e 5 , uma matéria ocupando duas páginas intitulada: "Tudo terminou em festa. E lágrimas", composta por $2 \mathrm{col} \times 16,5 \mathrm{~cm}$ mais 4 fotos. $\mathrm{Na}$ mesma página 5 “Rigotto admitequeo sonho caiu por terra" em $2 \mathrm{col} \times 15,5 \mathrm{~cm}$. A página 6 traz "O salto do caçula da família Vargas" composta por $2 \mathrm{col} \times 25 \mathrm{~cm}$ mais 3 fotos. Por fim o "Estilo Pepe de governar Caxias"em 2 col x 20,5cm euma foto. A baixo, um box de 3 $x 13 \mathrm{~cm}$. Na contra-capa, a charge do personagem Radicci, saudando Pepe Vargas e mais um artigo do editor - chefe: "Caxias vive tempo de mudanças".

\section{Conclusão}

A pesquisa sobrea hipótese deagenda-setting e sua aplicação empírica foi válida principalmenteparater-seumanoçãoclaradecomo esta teoria, que foi estudada exaustivamente duranteo período deaulaetambémnotempo que antecedeu a feitura desta monografia, tem sua função clara na conjuntura dos mass mídia.

A bordando especificamente o processo empírico da pesquisa, notamos que esta el eição teve seu agendamento consolidado a partir do segundo turno, quando a principal disputa, de Porto Alegre, encerrou com a vitória do candidato Raul Pont (PT). A partir deste instante, o Correio do Povo passou a destacar com maior espaço a disputa que representavaduasforças dapolítica estadual.

Quanto ao jornal local, Pioneiro, conduziu o processo de agendamento desde o início da campanha, refletindo o clima de disputa acirrada que se delineava na cidade. $O$ retrospecto dos dois candidatos também foi favorável eajudou na condução dos debates. De um lado, Germano Rigotto, ex-líder do governo Fernando Henrique (embora de partido diferente), e de outro, Pepe Vargas, um dos deputados estaduais mais votados em 1994. Sem contar os percal ços deambosna disputa da prefeitura de Caxias do Sul: uma derrota para cada.

A estratégia do Pioneiro não se deu somente naesfera local. Respaldado pela empresa que o gerencia (RBS), o jornal levou a eleição 
municipal para fora da cidade. Mais precisamente, quando fez a cobertura dos dois debates na rádio Gaúcha, em Porto Alegre, fazendo com que a el eição local alcançasse a hipótese de agenda-setting.

O que regeu os debates e por conseguinte a essência das matérias foram os prós econtras dos problemas nacionais relacionados no campo local. O fato de Germano Rigotto ter participado do governo de Fernando Henrique Cardoso foi o principal argumento utilizado por Pepe Vargas para desafiá-lo. Este, por sua vez, utilizou este argumento para defender-se dos ataques e enaltecer as idéias que defende.

Por outro lado, nas matérias analisadas, notamos pouca veiculação de problemas locais. A maioria das mesmas matérias trazia notícias sobre o cotidiano dos candidatos tal como:o quevisitou, o quefez, etc. Problemas como saúde, educação, habitação, finanças, quasenão al cançaram espaço nos doisjornais analisados.

Mesmo assim, podemos afirmar que a realização desta pesquisa alcançou os principais objetivos. O agendamento das eleições municipais de Caxias do Sul teve repercussão namídia não somenteno Estado, mas também no centro do país. Um fator peculiar que contribui, a nosso ver, para a composição deste quadro, foi o grau de parentesco entre Pepe Vargas e Germano Rigotto .

\section{Notas}

1 McCombs, Maxwell and Shaw, Donald. "The agendasetting function of mass-media". Public O pinion Quarterly. Vol. 36. №2, 1972, p. 176-187.

2 Barros Filho, Clóvis. Ética na Comunicação: da informação ao receptor. São Paulo, Editora Moderna, 1996. p. 169.

3 Idem. 0p. cit. p. 175.
4 McCombs, Maxwell et Shaw, Donald. Op. cit. p. 178.

5 Barros Filho, Clóvis. Op. cit. p. 178.

6 McCombs, Maxwell et Shaw, Donald. Op. cit. p. 184.

7 Defleur, Melvin et Ball-Rokeach, Sandra. "The agendasetting function of press: telling us what to think about". In: Milestones in mass communication reseach. New York, Langman, 1983.

8 Idem. Idem. p. 322.

9 DeFleur, Melvin et Ball-Rokeach, Sandra. Op. cit. p. 335.

10 McCombs, Maxwell. "Setting theagenda for agenda-setting reseach: an assesment of the priority ideas and problems". In: Whilhoit G. (ed), M ass Communication Review Yearbook, vol. 2. Sage, Berverly Hills. p 211.

11 Wolf, Mauro. Teorias da comunicação. Lisboa, Editorial Presença, $4^{4}$ edição, 1995. p. 148.

12 McClure, R. et Patterson, T. "Print vs N etwork News". In: Journal of Communications, vol. 26, no2, p. 23-28.

13 Wolf, Mauro. Op. cit. p. 134.

14 Wolf, Mauro. Op. cit. p. 134.

15 De Fleur, Melvin and Ball-Rokeach, Sandra. O p. cit. p. 347.

16 DeFleur, Melvin et Ball-Rokeach, Sandra. Op. cit. p. 349.

17 Idem. Op. cit.p. 349.

18 Barros Filho, Clóvis. Op. cit.p. 191.

19 Idem. p. 191.

20 Barros Filho, Clóvis. Op. cit. p. 191

21 Defleur, Melvin et Ball-Rokeach, Sandra. Op. cit. p. 349.

22 Estes dados foram extraídos do jornal Pionero, um dos utilizados para o estudo de caso.

23 Borba e Albuquerque, Dhynarte de. "Pesquisas eleitorais têm idoneidade". Pionero. Caxias do Sul, Ano 48, no6.516. 25 de outubro de 1996. p. 10. 
24 Borba e Albuquerque, Dhynarte de. 0p. cit. p. 10.

25 João Inácio Pires Lucas. Depoimento a Dhynarte de Borba e Alburqueque. 0 p. cit. p. 10

26 Borba e Albuquerque, Dhynarte de. 0p. cit. p. 10.

27 Martini, Rafael. "Inicia temporada de caça ao voto". Caxias do Sul, Pioneiro - Caderno Eleições 96. Ano 48, n-6.445. p. 2.

28 "Interesse pela eleição é baixo". Caxias do Sul, Pioneiro Caderno Eleições 96. Ano 48, no6.450. p. 1.

29 Importante ressaltar que este caderno não teve uma publicação regular durante a campanha. Algumas das edições analisadas não continham o caderno, mas sim as matérias publicadas normalmente com outras editorias.

30 Martini, Rafael. "Temas nacionais centralizam debate". Caxias do Sul, Pioneiro - Caderno Eleições 96. Ano 48, n6.486. p.1.

\section{Referências}

BARROS FILHO, Clóvis de. Ética na comunicação - da informação ao receptor. São Paulo, Editora Moderna, 1996.

DEFLEUR, Melvin et BALL-ROKEACH, Sandra. "The agendasetting function of thepress:Telling us what to think about". In: Milestones in M ass Communication Reseach, New York, Langman, 1983.p. 327- 352.

McCOMBS, Mawxell E. etSHAW, Donald. "Theagenda-setting function of mass media". In: Public O pinion Quarterly. Vol. 36, №2, Summer, 1972, p. 176-187.

WOLF, Mauro. Teorias da comunicação. Lisboa, Editorial Presença, 1995.

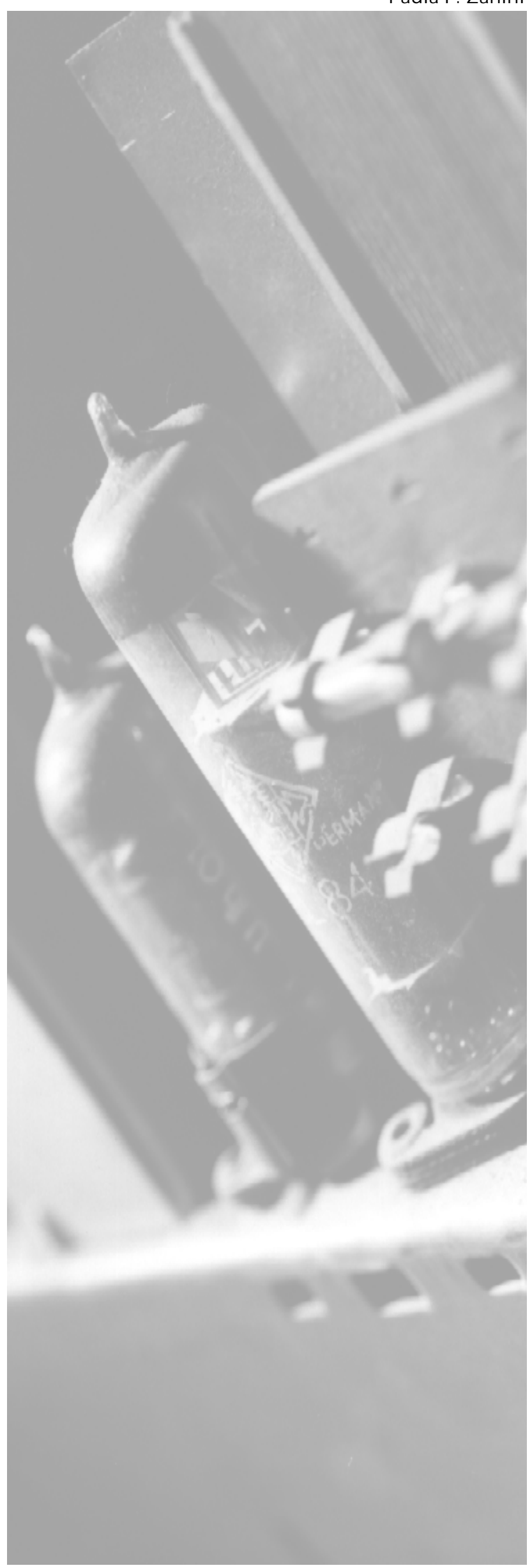

